\title{
Professoras negras na pós-graduação em saúde: entre o racismo estrutural e a feminização do cuidado
}

\author{
Black female professors in health postgraduate courses: between \\ structural racism and the feminization of care
}

\author{
Ana Lucia Nunes de Sousa', Luciana Ferrari Espíndola Cabra|1,2, Janine Monteiro Moreira', \\ Valentina Carranza Weihmüller', Marina Meloni da Silva Rodrigues³, Gabriela Gomes Araujo', \\ Beatriz Cristina Castro Macedo 2
}

DOI: 10.1590/0103-11042021E101

\begin{abstract}
RESUMO A partir de referenciais do feminismo negro, da perspectiva interseccional e dos estudos étnico-raciais no Brasil, problematizam-se o racismo e o sexismo na academia brasileira com base na caracterização e análise da presença/ausência de professoras negras em programas de pós-graduação em ciências da saúde de duas universidades federais fluminenses, UFRJ e UFF. Utilizando informações de sites de 31 Programas de Pós-Graduação (PPG), reconstruíram-se quantitativamente os perfis de gênero e étnico-raciais por universidade e área de avaliação. Identificaram-se 23 professoras negras que ocupam 26 vagas docentes nos PPG analisados. Com base em informações da Plataforma Lattes, também se abordou longitudinalmente a dimensão de estudo. Os resultados assinalam que a presença de professoras negras é de $2 \%$ na UFRJ e de $6 \%$ na UFF; que ela é maior em áreas relativas aos cuidados e ínfima em áreas de maior prestígio científico e socioeconômico, como medicina. Constata-se o racismo como principal sistema de poder, operando no contexto institucional e disciplinar. Neste último, associado ao sexismo que determina as hierarquias de gênero nas áreas de saúde. Observa-se, também, que as desigualdades de raça se sobrepõem às de gênero no contexto desta pesquisa, confirmando as teses que apontam o epistemicídio dos saberes negros.
\end{abstract}

PALAVRAS-CHAVE Racismo. Sexismo. Ciências da saúde. Interseccionalidade. Instituições de Ensino Superior.

1 Universidade Federal do Rio de Janeiro (UFRJ), Instituto Nutes de Educação em Ciências e Saúde (Nutes) - Rio de Janeiro (RJ), Brasil. anabetune@gmail.com

${ }^{2}$ Centro Federal de Educação Tecnológica Celso Suckow da Fonseca (Cefet) - Rio de Janeiro (RJ), Brasil.

${ }^{3}$ Centro Universitário Senac - São Paulo (SP) Brasil.

\begin{abstract}
Based on black feminism, intersectional perspective and Brazilian ethnic-racial studies, the paper problematized racism and sexism in the Brazilian academy. It characterizes and analyses the presence/ absence of black women professors in PhD programs in health sciences of two federal universities, UFRJ and UFF. Using information from the websites of $31 \mathrm{PhD}$ programs, we reconstructed, quantitatively, the gender and ethnic-racial profiles of the PhD programs by university and evaluation area. Twenty-three black women professors were identified in 26 teaching positions. Based on information from the Plataforma Lattes, we also addressed the study dimension longitudinally. The results indicate that the presence of black women professors is $2 \%$ at UFRJ and $6 \%$ at UFF. It is greater in areas related to care, and non-existent in areas of greater scientific and socio-economic prestige, such as Medicine. Racism is seen as the main power system, operating in the institutional and disciplinary context. In the latter, it is associated with sexism that determines gender hierarchies in health fields. It is also observed that race inequalities overlap with gender inequalities in the context of this research, confirming the theses that point to the epistemicide of black knowledge.
\end{abstract}




\section{Introdução}

A população brasileira é estimada em mais de 200 milhões de pessoas ${ }^{1}$, das quais $52,1 \%$ são negras (pretas ou pardas); e 0.47\% são indígenas, de acordo com dados do último censo do Instituto Brasileiro de Geografia e Estatística (IBGE) ${ }^{2}$. A diversidade étnico-racial e linguística do Brasil deveria apontar também para uma multiplicidade em perspectivas, teorias, métodos, objetos e sujeitos no universo acadêmico. Entretanto, não é isso que se observa na prática.

Dados do Censo da Educação Superior de $2016^{3}$ revelam que pessoas pretas ou pardas são apenas $30 \%$ das que recebem algum tipo de bolsa de pesquisa do Conselho Nacional de Desenvolvimento Científico e Tecnológico (CNPq), quando representam mais da metade da população. Deve-se considerar, ainda, que a maior parte dessas bolsas são de iniciação científica, em que - devido à aplicação de ações afirmativas nos últimos anos ${ }^{4}$ - o acesso de pessoas pretas e pardas aumentou.

Em relação ao número de doutores e doutoras, Venturini ${ }^{5}$ afirma que, entre as pessoas que declararam sua raça e/ou cor nos dados divulgados pelo CNPq, a configuração seria: $79,01 \%$ brancas; $15,29 \%$ pardas; $3,05 \%$ pretas; $2,22 \%$ amarelas; e 0,42\% indígenas. Quando se analisam os dados com recorte de gênero, considerando apenas as pessoas que se declaram do sexo feminino, a disparidade aumenta: $80,02 \%$ brancas; $14,60 \%$ pardas; $2,75 \%$ pretas; $2,35 \%$ amarelas; e 0,28\% indígenas. Nos Programas de Pós-Graduação (PPG), as doutoras negras (pretas e pardas) somam apenas 3\% de todos os docentes em atividade no País ${ }^{6}$.

No caso do estado do Rio de Janeiro, reportagem publicada na revista 'Gênero e Número', em 2018, apontava a existência de 18 doutoras autodeclaradas negras, atuando como docentes em cursos de pós-graduação stricto sensu (mestrado e doutorado). Há, portanto, uma evidente sub-representação de mulheres negras na categoria 'professor do magistério superior'.

Com o objetivo de aprofundar o estudo sobre mulheres negras nos espaços de produção científica e formação profissional em saúde, este trabalho se propõe a refletir sobre a presença/ausência de professoras negras credenciadas em PPG da área de ciências de saúde, de duas universidades federais fluminenses: a Universidade Federal do Rio de Janeiro (UFRJ) e a Universidade Federal Fluminense (UFF). Pergunta-se, especificamente: como se configura sua presença/ausência nos PPG da área de ciências da saúde? Qual sua presença/ ausência em contextos institucionais e disciplinares? Como os sistemas de poder relativos à raça (racismo) e ao gênero (sexismo) condicionam o acesso e o lugar das professoras negras nos PPG analisados? Como se manifesta a intersecção entre ambos?

\section{Mulheres negras e cuidado}

Um estudo sobre a demografia médica no Brasil 7 mostra que os homens são $54,4 \%$ dos médicos atuando no País. Contudo, em algumas áreas de 'maior prestígio', como a cirurgia, o domínio masculino chega a $70 \%$. Entre as pessoas recém-graduadas, a pesquisa revela que apenas $1,8 \%$ se declaram pretas, enquanto $16,2 \%$ se dizem pardas. O quadro que se delineia é, então, de uma medicina branca e masculina. Em outras áreas das ciências da saúde, como a enfermagem, o quadro é o oposto. As mulheres são $84,6 \%$ da força de trabalho, sendo que 53\% se declaram pretas ou pardas 8 .

Segundo Almeida ${ }^{9}$, o Brasil colonial deixou de legado para as mulheres negras as práticas de cuidado e cura. Entretanto, com a normatização da profissão, no início do século XX, o acesso de pessoas negras à formação foi inicialmente impedido ${ }^{10}$, e muitas mulheres se encaminharam para os cursos técnicos. Delineou-se um abismo social entre negros e brancos, que incidiu diretamente nas posições ocupacionais no País. Ainda assim, enfrentando todas essas barreiras, as mulheres negras conseguiram acessar a formação superior na área de ciências da saúde. Os registros da Faculdade de Medicina da Bahia indicam que 
Maria Odília Teixeira teria sido a primeira médica negra do Brasil, diplomada em 1909. Na Faculdade de Enfermagem Anna Nery, no Rio de Janeiro, por sua vez, há registros do ingresso da primeira estudante de enfermagem negra em $1926^{8}$.

Em que pese o racismo que atuou impedindo a profissionalização das mulheres negras nas áreas de maior prestígio, elas continuaram dedicando-se amplamente às áreas do cuidado, seguindo ensinamentos ancestrais. Por outro lado, compreende-se que o racismo normatiza as ações na esfera estrutural, reproduzindo e justificando o maior quantitativo de mulheres negras nas ocupações de cuidado. A ocupação de mulheres negras no campo da enfermagem é exemplo maior da reprodução da normativa hetero-cis-patriarcal-racista do sistema vigente?

\section{O racismo estrutural}

Para Almeida"11, o racismo é moldado no inconsciente coletivo, por meio do desenvolvimento de um imaginário social no qual os negros estão sempre em papéis subalternizados. $\mathrm{O}$ autor considera que a vida social é mediada pela ideologia racista, por meio de um imaginário reproduzido sistematicamente pelos sistemas comunicacional, educacional e judiciário e em consonância com a realidade, uma vez que, apesar das generalizações exibidas nas telenovelas, por exemplo, a maioria das empregadas domésticas e das pessoas encarceradas é negra. Ao mesmo tempo, a maior parte das posições de liderança das empresas públicas e privadas está ocupada por homens brancos.

Por sua vez, a lógica meritocrática reafirma no imaginário coletivo a ideia de que competência, inteligência e mérito estão intimamente ligados à branquitude - e, também, à masculinidade, à heterossexualidade e à cisnormatividade. Para o autor, é dessa maneira que se constrói no imaginário coletivo a ideia de que os negros - e, em especial, as mulheres negras - são menos capazes de exercer profissões altamente intelectualizadas. Em palavras do autor:

O racismo é uma decorrência da própria estrutura social, ou seja, o modo 'normal' com que se constituem as relações políticas, econômicas, jurídicas e até familiares, não sendo uma patologia social e nem um desarranjo institucional. O racismo é estrutural. Comportamentos individuais e processos institucionais são derivados de uma sociedade cujo racismo é regra e não exceção. O racismo é parte de um processo social que ocorre pelas costas dos indivíduos e lhes parece legado pela tradiçãon(150).

Pode-se associar o baixo percentual de pesquisadoras negras nos PPG, na atualidade, ao somatório dos fenômenos que Almeida ${ }^{11}$ chama de discriminação direta e indireta. Segundo o autor, a discriminação direta pressupõe um tratamento que provoca desvantagem para a pessoa discriminada. Já a discriminação indireta é marcada pela ausência dessa intencionalidade explícita (ou publicizada), e pode se dar por intermédio de processos em que a situação específica de grupos minoritários é ignorada, por meio da execução de uma sucessão de regras relacionadas com uma suposta neutralidade racial.

Ambas as formas de discriminação são resultantes do racismo estrutural, e suas práticas, em médio e longo prazo, levam à estratificação social, diminuindo as chances de ascensão de todo o grupo. Sendo o racismo inerente à ordem social e presente no cotidiano, caso as instituições não implementem práticas antirracistas efetivas, elas fatalmente o reproduzirão. Dessa forma, pode-se inferir que essas mesmas instituições tendem a ignorar a lógica interseccional que atravessa os corpos das mulheres negras.

Sueli Carneiro ${ }^{12}$ relaciona a reprodução do racismo nos processos seletivos aos cargos no serviço público e vagas nas universidades públicas com o efeito das políticas universalistas que, no Brasil, perpetuaram os privilégios dos grupos mais favorecidos, leia-se 
dos indivíduos brancos. Ela defende a necessidade de ações afirmativas em oposição à falácia meritocrática. Segundo a autora, ao se invocar o mérito para impedir o desenvolvimento e a execução de propostas capazes de promover a equidade racial, omite-se uma construção social na qual "nascer branco consiste por si só num mérito, uma vantagem adicional cujo prêmio é conduzir naturalmente os brancos ao acesso privilegiado dos bens sociais"12(105).

Carneiro ${ }^{12}$ apresenta um conjunto de dados que corrobora esse argumento. O Índice de Desenvolvimento Humano (IDH), calculado apenas com os dados da fração da população que se autodeclara branca, apresenta um padrão de desenvolvimento semelhante ao de países como a Bélgica. Entretanto, o mesmo cálculo feito com os dados da população que se autodeclara negra resulta em níveis inferiores aos de outros países em desenvolvimento como a África do Sul.

Dados atualizados do IBGE ${ }^{13}$ indicam a manutenção desse quadro. De acordo com dados do Instituto sobre a distribuição da população desocupada por cor ou raça, no primeiro trimestre de 2019, 63,9\% dos desempregados no Brasil eram pretos ou pardos. Outro dado que mostra o abismo que separa brancos e negros é a taxa de analfabetismo: na população negra entre 15 e 60 anos, ela alcança $9,1 \%$, enquanto atinge apenas 3,9\% da população branca entre 15 e 60 anos $^{14}$.

Os dados apresentados por Carneiro ${ }^{12}$ mostram que, no mercado de trabalho formal, as mulheres negras recebem, em média, metade da renda média das mulheres brancas; que, por sua vez, recebem mais que um homem negro e cerca de $50 \%$ do rendimento médio dos homens brancos. Aqui, mais uma vez, Carneiro ${ }^{12}$ chama a atenção para a dimensão racial do gênero, já que os dados demonstram uma dinâmica específica que imprime desvantagens entre as mulheres. Em outras palavras, sobre as mulheres negras, recai o impacto das opressões racista, sexista e de classe, de forma conjunta e indissociável.

\section{Racismo e sexismo}

Em pesquisa sobre a atuação de doutoras negras no espaço acadêmico brasileiro, da Silva ${ }^{15}$ revelou que, na época, em todo o País, havia 251 doutoras negras na base do Sistema Nacional de Avaliação da Educação Superior (Sinaes) - que agregava os dados do Censo Nacional de Educação Superior. Com base na análise dos currículos Lattes dessas pesquisadoras, o estudo revelou que a promoção das mulheres negras na carreira enfrentava mais dificuldades quando comparada à de suas pares brancas. Além disso, a pesquisa apontou o 'fenômeno da superqualificação'15, já que as mulheres negras tendiam a ser alocadas em lugares abaixo da sua formação acadêmica. Nesse sentido, a pesquisadora argumenta que seria uma consequência de dois fatores interligados: o racismo e o sexismo, que atuariam como ferramenta de exclusão social.

Sexismo e racismo se apresentam de forma conjunta e indissociável na vida de mulheres negras, gerando uma 'asfixia social' 12 que gera consequências em todas as áreas da vida dessas mulheres. Em pesquisa recente sobre como mulheres cientistas estão sendo afetadas em sua produtividade pela pandemia da Covid-19, o coletivo Parent in Science ${ }^{\mathbf{1 6}}$ apontou como as pesquisadoras negras, independentemente de terem filhos ou não, foram as que encontraram maiores dificuldades neste período. Isso corrobora a tese de Davis 17(26), quando afirma que "não existe uma feminilidade abstrata que sofre o sexismo de forma abstrata e que luta contra ele em um contexto histórico abstrato", por isso, ao analisar os efeitos do sexismo, é fundamental não o separar das dimensões racial e socioeconômica.

Dessa forma, o sexismo, o racismo, a opressão de classe e outros sistemas de poder criam desigualdades estruturantes que determinam as posições relativas de mulheres, raças e classes $^{18}$. Trata-se de um fenômeno de discriminação observado em múltiplas camadas sobrepostas. Crenshaw ${ }^{19}$ explica que ocorre uma discriminação mista, composta, que 
combina o peso da discriminação racial com o peso da discriminação de gênero ${ }^{19}$. A autora coloca que, em determinadas situações, a raça pode ser uma condição capaz de determinar a credibilidade dada a mulheres, de tal forma que a condição racial pode, eventualmente, sobrepor-se ao gênero, colocando as mulheres negras em condição de maior desvantagem quando comparadas às mulheres brancas.

Para Collins ${ }^{\mathbf{2 0}}$, a interseccionalidade permite ver como os três sistemas - raça, classe e gênero - se entrelaçam para estruturar a dimensão institucional da opressão. Essa perspectiva, também segundo a socióloga, evitaria com que se caísse nos equívocos gerados pelas análises somatórias ou aditivas de opressão, que tendem a quantificar a opressão, gerando a ideia de que um grupo é mais oprimido do que outro. Entretanto, ela também pontua, assim como Crenshaw, que se deve reconhecer que uma categoria pode ter primazia sobre outras por determinado tempo e lugar, o que não minimiza a importância teórica da interseccionalidade. Ou seja, mesmo que os dados revelem que, em determinado momento, uma determinada opressão possa ser predominante, isso não quer dizer que o entrelaçamento entre elas não exista. Uma perspectiva analítica que considere a combinação do racismo estrutural11 e o efeito da interseccionalidade na discriminação por gênero, raça e classe fornece subsídios para compreender os fenômenos sociais por trás do baixo número e invisibilização das mulheres negras atuando como pesquisadoras profissionais nas instituições públicas de ensino e pesquisa no Brasil.

bell hooks ${ }^{21}$ também chama a atenção para a invisibilidade e as dificuldades encontradas por mulheres negras intelectuais no mundo acadêmico. Tanto hooks quanto González 22 argumentam como os estereótipos racistas influenciam na construção do imaginário social sobre as mulheres negras, fazendo com que sejam sexualizadas, animalizadas e colocadas apenas no lugar de 'cuidadoras', deslegitimando-as, portanto, como intelectuais. Para hooks 21(468),
O sexismo e o racismo atuando juntos perpetuam uma iconografia de representação da mulher negra que imprime na consciência cultural coletiva a ideia de que ela está neste planeta principalmente para servir aos outros.

Assim, constrói-se nesse imaginário uma interdição da academia às mulheres negras, rotineiramente vistas como um "corpo sem mente" 20(469), um processo de negação da intelectualidade do 'outro'.

\section{Mulheres negras e a luta pelo conhecimento}

Apesar de ainda concentrar as maiores taxas de analfabetismo, a luta por educação sempre esteve no horizonte do povo negro. Segundo Davis ${ }^{23}$, a educação sempre foi uma prioridade para o povo negro que, após séculos de privação educacional, reivindicaram - e continuam exigindo - seu direito à educação de forma tenaz. A luta por receber instrução acadêmica sempre foi, para o povo negro, parte de sua batalha coletiva por liberdade.

No Brasil, principalmente a partir do período pós-abolição, a educação passou a ser uma luta prioritária ${ }^{24}$. A ascensão social pela via educacional é uma constante no imaginário social do povo negro no País. Essa foi, inclusive, uma das batalhas constantes dos movimentos negros organizados. A Frente Negra Brasileira (FNB), fundada em 1931, por exemplo, tinha na educação um de seus pilares. Assim, atuou na alfabetização de crianças, jovens e adultos, além de abrir escolas por todo o País, até sua extinção, em 1937, pela ditadura de Getúlio Vargas. Outras organizações, como o Teatro Experimental do Negro e o Movimento Negro Unificado ainda na ativa -, atuaram fomentando a arte, a cultura e educação, sendo de importância cabal para a emergência de uma intelectualidade negra.

hooks ${ }^{21}$ argumenta como o trabalho intelectual é importante para a luta pela 
libertação de todas as pessoas oprimidas e/ ou exploradas, pois, ao passar de objeto a sujeito, descolonizam e libertam suas mentes. Ratts $^{\mathbf{2 5 ( 2 9 )}}$ aponta como esses corpos negros, nesse movimento, também se tornam agentes políticos de uma luta coletiva, pois, ao adentrar o espaço acadêmico, passam a atuar de forma individual e coletiva, colocando em prática um "projeto político acadêmico que tem memória e história".

Entretanto, o pesquisador também denuncia que

Há um notório incômodo com os corpos negros, corpos que pensam, que propõem esse debate, e com as corporeidades negras que estão adentrando a universidade ${ }^{25(29) .}$

Euclides, Santos Silva e da Silva ${ }^{26}$ corroboram o argumento quando sugerem que, ao alcançar esse espaço, esses corpos de mulheres negras precisam provar sua capacidade, sempre questionada pela branquitude, desempenhando um grande esforço para serem reconhecidas. É nesse sentido que hooks ${ }^{21}$ defende a construção de estratégias para que as mulheres negras tenham o devido reconhecimento de sua inteligência e excelência como um passo importante no processo de reeducação e emancipação da sociedade, com vistas a extirpar as opressões raciais, de gênero e econômica.

Assim, uma investigação que objetive refletir sobre as presenças e ausências de mulheres negras, pesquisadoras, intelectuais na área das ciências da saúde trilha os caminhos apontados por hooks ${ }^{21}$. É importante frisar como a comunidade acadêmica, em sua maioria, parece não se surpreender com o fato de que, em grande parte dos PPG do País, a presença de profissionais negras é muito pequena ou inexistente. Pelo contrário, como afirma Carneiro ${ }^{12}$, considera-se satisfatório que uma ou outra mulher negra se destaque, sendo que esses casos ainda são utilizados para desqualificar as denúncias de exclusão social e racial no campo acadêmico.

\section{Material e métodos}

As tarefas metodológicas se dividiram em duas etapas, que utilizaram como fontes de dados informações disponíveis em plataformas institucionais on-line. Realizou-se a coleta, a sistematização e o tratamento de informações públicas, extraídas dos sites oficiais dos PPG e dos currículos Lattes das pesquisadoras negras identificadas. As variáveis consideradas foram quantitativas, procurando: 1) reconstruir o perfil étnico-racial (negro, não negro) e de gênero (homens, mulheres) de cada PPG; 2) reconstruir a dimensão longitudinal do fenômeno. As coletas foram realizadas manualmente e se limitaram às informações disponíveis nos sites institucionais explorados.

A pesquisa foi iniciada com a seleção, na Plataforma Sucupira, dos PPG stricto sensu da área de avaliação 'Ciências da Saúde', que englobam os cursos das Instituições de Ensino Superior analisadas (UFRJ e UFF): Educação Física, Enfermagem, Farmácia, Nutrição, Odontologia, Saúde Coletiva, Medicina I (programas multidisciplinares e especialidades clínicas em Oncologia, Cardiologia, Endocrinologia, Nefrologia, Pneumologia, Gastroenterologia e Hepatologia), Medicina II (Doenças Infecciosas e Parasitárias, Patologia, Pediatria, Neurologia, Psiquiatria/ Saúde Mental, Radiologia, Hematologia, Reumatologia e Alergologia) e Medicina III (área cirúrgica e Anestesiologia) ${ }^{27}$. Esse levantamento resultou em $31 \mathrm{PPG}$, sendo 20 da UFRJ e 11 da UFF.

A primeira etapa consistiu em conhecer o perfil étnico-racial e de gênero de cada PPG e identificar as pesquisadoras negras credenciadas. Assim, exploraram-se os sites institucionais dos PPG selecionados, nas seções 'docentes'/‘corpo docente', contabilizando: o número de professores/as; o número por subgrupos de 'gênero' (homens e mulheres), e 'gênero e raça' (mulheres negras e homens negros). Para essa classificação, utilizaram-se como critérios o gênero do nome próprio de cada professor/a (feminino ou masculino) e 
a fotografia disponível em páginas oficiais. Além disso, foi criada uma comissão de verificação das características fenotípicas para estabelecer a identificação racial (negro ou não negro), a partir da foto do docente disponível no mesmo site, no Curriculum Lattes ou outra fonte on-line (ResearchGate, Academia.com, LinkedIn). Não foram encontradas fotografias confiáveis para realizar o processo de heteroidentificação de 22 docentes mulheres e de 20 docentes homens da UFRJ; e de 34 docentes mulheres e de 14 docentes homens da UFF. A verificação foi realizada por três pesquisadoras, seguindo os parâmetros estabelecidos institucional e legalmente pelas comissões de heteroidentificação atuantes nos últimos anos, em algumas universidades públicas do País ${ }^{28}$. O processo de verificação das/os docentes realizou-se em duas etapas, objetivando a consolidação dos dados coletados. É importante mencionar que a equipe da pesquisa passou por treinamento em heteroidentificação, realizado com o apoio da Câmara de Políticas Raciais da UFRJ.

Os dados de cada PPG foram organizados em planilhas Google Sheets sistematizando as seguintes variáveis:

- Universidade;

- Nome do PPG;

- Área de avaliação;

- $\mathrm{N}^{\mathrm{o}}$ professores/pesquisadores total;

- $\mathrm{N}^{\mathrm{o}}$ professores/pesquisadores homens;

- $\mathrm{N}^{\mathrm{o}}$ professoras/pesquisadoras mulheres;

- $\mathrm{N}^{\mathrm{o}}$ professoras/pesquisadoras mulheres negras;

- $\mathrm{N}^{\circ}$ professores/pesquisadores homens negros;

- $\mathrm{N}^{0}$ professores/pesquisadores sem identificação;
- $\mathrm{N}^{0}$ professoras/pesquisadoras sem identificação.

Com esses dados, foi possível construir indicadores estimativos da presença das professoras/pesquisadoras negras para cada PPG e instituição. Foram verificadas 23 professoras negras, ocupando 10 vagas na UFRJ e 16 na UFF (nos Programas de Enfermagem da UFF, duas docentes ocupam vagas em mais de um Programa). As informações obtidas do processo de coleta e sistematização foram organizadas visualmente em tabelas e gráficos para apresentação e análise.

Para aprofundar as reflexões do estudo, também se analisou a dimensão longitudinal do fenômeno, por meio do indicador 'data de ingresso nos PPG', obtido a partir de informações dos Curriculum Lattes das pesquisadoras. Logo, foram apresentados em gráfico linear (1995-2019) e comparativo, considerando ambas as universidades.

\section{Resultados e discussão}

A quase inexistência de professoras/pesquisadoras negras nas vagas docentes nos PPG analisados é evidenciada nos dados apresentados. O gráfico 1 apresenta os dados dos corpos docentes dos PPG analisados da UFRJ e UFF, de acordo com o gênero e o grupo étnico-racial (negros e não negros) dos/as docentes que ocupam vagas. Observa-se que as mulheres são maioria, representando $60 \%$ na UFRJ e $63 \%$ na UFF.

O corpo docente da UFRJ apresenta quase $o$ dobro das docentes da UFF, mas o número absoluto de docentes negros e negras ocupando vagas é discretamente maior nesta última. São 18 docentes negros e negras na UFRJ, de um total de 472 profissionais nos $\mathrm{PPG}$, dos quais apenas 10 são mulheres negras, ou seja, $2 \%$ do total. Já na UFF, o corpo docente é menor, 273 professores/as nos PPG, sendo 16 das vagas ocupadas por professoras negras, correspondente a $6 \%$ do total de vagas docentes. 
Quando analisamos apenas as vagas docentes ocupadas por mulheres, na UFRJ, as pesquisadoras negras representam $3,58 \%$; e na UFF, 9,3\%. Porém, ao analisar somente o grupo étnico-racial negro, as vagas ocupadas por mulheres são maioria; sendo 55,5\% na UFRJ e $80,0 \%$ na UFF. Esses indicadores confirmam, portanto, Davis ${ }^{17}$ e Carneiro ${ }^{12}$, quando chamam a atenção para a racialização do gênero. Em outras palavras, o baixo percentual de mulheres negras como pesquisadoras profissionais dos PPG das áreas revela que, mais do que um problema de gênero, há uma invisibilidade racial profunda no acesso a esses postos de trabalho e poder.

Gráfico 1. Características de gênero/étnico-racial de vagas docentes dos PPGs de saúde da UFRJ/UFF

UFRJ

\section{$\mathrm{N}$ docentes $=472$}

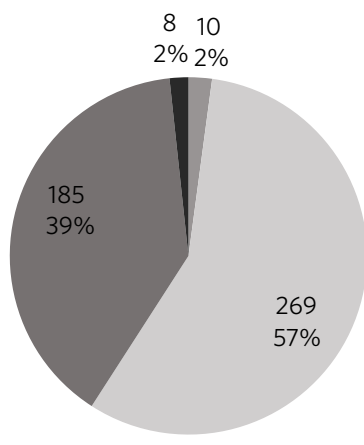

Professoras negras

Professoras não-negras

Professores não-negros

Professores negros

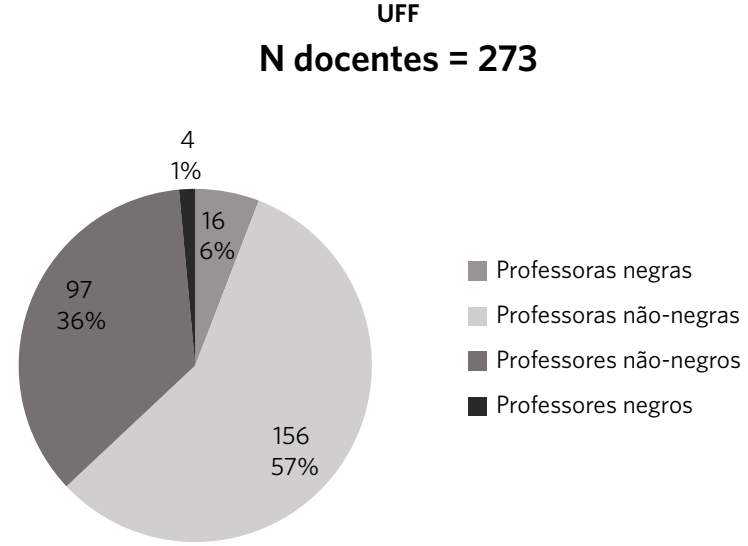

UFF

$\mathrm{N}$ docentes $=\mathbf{2 7 3}$

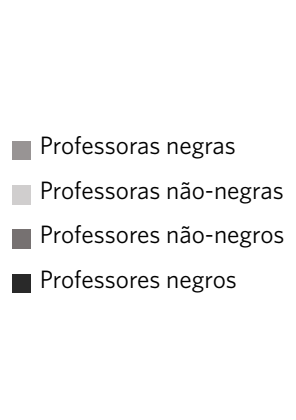

A partir desses dados, observa-se que o caráter racial se sobrepõe ao gênero na ocupação das vagas. As vagas, em ambos os casos, são ocupadas majoritariamente por indivíduos brancos, confirmando as teses de Almeida ${ }^{11} \mathrm{e}$ Carneiro ${ }^{\mathbf{1 2}}$, quando afirmam que o racismo estrutural se apoia na discriminação indireta, que alija corpos negros para fora das posições hierárquicas mais altas, reproduzindo a ordem de poder racista nos espaços de produção do conhecimento.

A interseccionalidade, proposta por Crenshaw ${ }^{\mathbf{1 8 , 1 9}}$ e Collins ${ }^{\mathbf{2 0}}$, defende que a análise das opressões não hierarquize as variáveis. Nesse sentido, o que analisamos, a partir dos dados apresentados, é o entrelaçamento das opressões de gênero e raça principalmente; sendo que, nesse caso específico, os dados demonstram que a opressão de raça acaba tendo primazia sobre os outros eixos de opressão, evidenciado em relação ao gênero. Tal possibilidade já havia sido aventada tanto por Crenshaw como por Collins e demonstra, na prática, a necessidade de uma análise detalhada dos dados.

No cômputo geral, em relação ao gênero, as mulheres são maioria nos PPG das duas universidades. No entanto, ao inserir a lupa racial nesses dados, o que se vê é que, se bem há mais mulheres do que homens, estas são, em sua maioria, mulheres brancas. As mulheres e os homens negros constituem os quadros minoritários em ambas as instituições. Mais adiante, essa análise será retomada. Diante 
disso, torna-se também evidente a importância das ações afirmativas raciais, visto que as trajetórias e produções intelectuais de pessoas negras não asseguram o acesso a posições hierárquicas altas.

Disso também se depreende que há um epistemicídio dos saberes negros - e principalmente do saber negro feminino e uma refutação à teoria da meritocracia imposta pelo sistema neoliberal, como já apontado por Sueli Carneiro ${ }^{12}$ e assinalado por da Silva ${ }^{15}$ em relação à 'superqualificação' das doutoras negras.

Gráfico 2. Características de gênero/étnico-racial de vagas docentes dos PPGs de saúde da UFRJ e UFF, segundo a área de avaliação

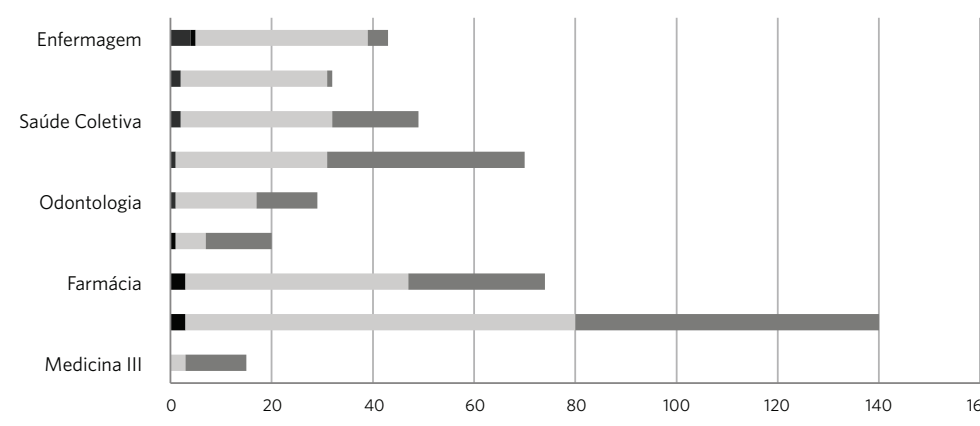

$$
\begin{aligned}
& \text { - Professoras negras } \\
& \text { - Professores negros } \\
& \text { Professoras não negras } \\
& \text { — Professores não negros }
\end{aligned}
$$

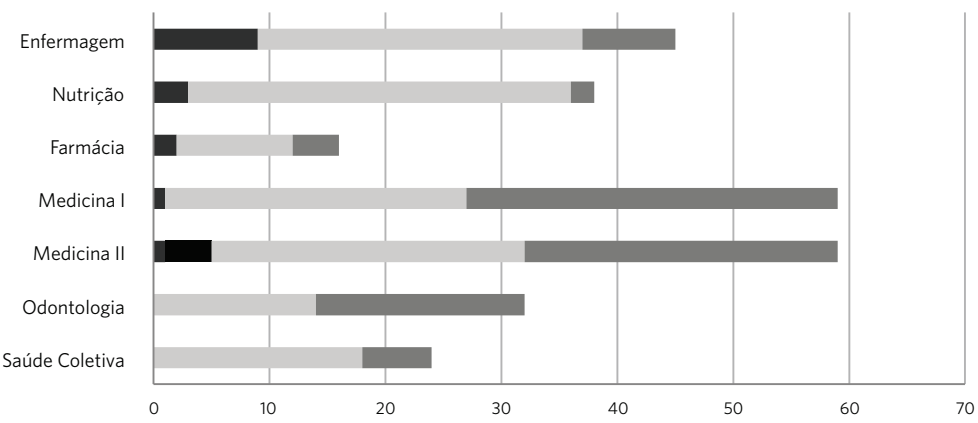

- Professoras negras

- Professores negros

Professoras não negras

- Professores não negros

No gráfico 2, apresentam-se os dados de vagas docentes por área de avaliação, desagregados nos quatro subgrupos de análise: professoras negras (cinza-escuro), professores negros (preto), professoras não negras (cinza-claro) e professores não negros (cinza-médio). Também, para cada área de avaliação (cada barra), apresenta-se a quantidade de docentes negras/total do corpo docente, e a porcentagem obtida dessa relação.
Observa-se que as mulheres predominam nas vagas das áreas de cuidado, como já apontado por Marcondes ${ }^{29}$. Aqui é importante pontuar que, ao desagregar os dados raciais, o argumento que já se apresentou fica evidenciado, pois não são 'as mulheres' que predominam nessa área, são as 'mulheres brancas'. Enquanto isso, nas áreas com mais prestígio social e econômico, como medicina, há um domínio quase absoluto de homens 
brancos. Na UFRJ, entre 225 docentes da área de medicina (I, II e III), encontrou-se apenas 1 vaga ocupada por uma professora negra; na UFF, entre 118 docentes da área de medicina, encontraram-se 2 vagas ocupadas por docentes negras. Ou seja, as professoras negras têm maior presença em áreas de cuidados, como enfermagem, seguindo a área de nutrição (relacionada também com temas 'femininos', como alimentação).

A partir dos dados de ambos os gráficos, é possivel reconhecer dois 'eixos contextuais' que condicionam a presença/ausência de doutoras negras nos corpos docentes dos PPG analisados. Esses eixos são: o 'institucional' e o 'disciplinar'. O primeiro refere-se às características de prestígio, status e disponibilidade de recursos das Instituições de Ensino Superior, pois, comparando os dados, na UFRJ (instituição de maior 'prestígio' e recursos), o número de doutoras negras é quase a metade do da UFF (gráfico 1).

Já o contexto disciplinar apresenta outros condicionantes relacionados com os estereótipos socioculturalmente assinalados às mulheres negras, como remarcam hooks ${ }^{21}$ e Gonzalez ${ }^{22}$. Assim, considerando áreas de avaliação (gráfico 2), é possível ver como a presença de doutoras negras é maior em áreas relativas a cuidados, como enfermagem.

No Brasil, esses cursos/profissões são de menor 'prestígio' quando comparados a, por exemplo, medicina e odontologia. Aliás, os dados apresentados evidenciaram como, nas áreas de avaliação específicas de medicina, o número de professoras e professores negros é baixo, quando não inexistente. Isso demonstra o componente racista não só no nível institucional, mas também no 'campo científico', dada a hierarquia médico-cêntrica-racista-sexista ainda vigente nas áreas/profissões de saúde.

Outro elemento se refere à feminização das profissões de saúde, o que influi em uma maior presença das pesquisadoras negras em relação aos pesquisadores negros. Assim, é possível pensar que o racismo opera de forma mais estrutural no contexto institucional, enquanto os estereótipos de gênero aparecem como condicionantes específicos do contexto disciplinar.

Gráfico 3. Evolução longitudinal de professoras negras em PPGs das áreas de saúde. UFF e UFRJ. 1996-2019. Valores acumulados por ano de ingresso como docente ao PPG. $\mathrm{N}=23$

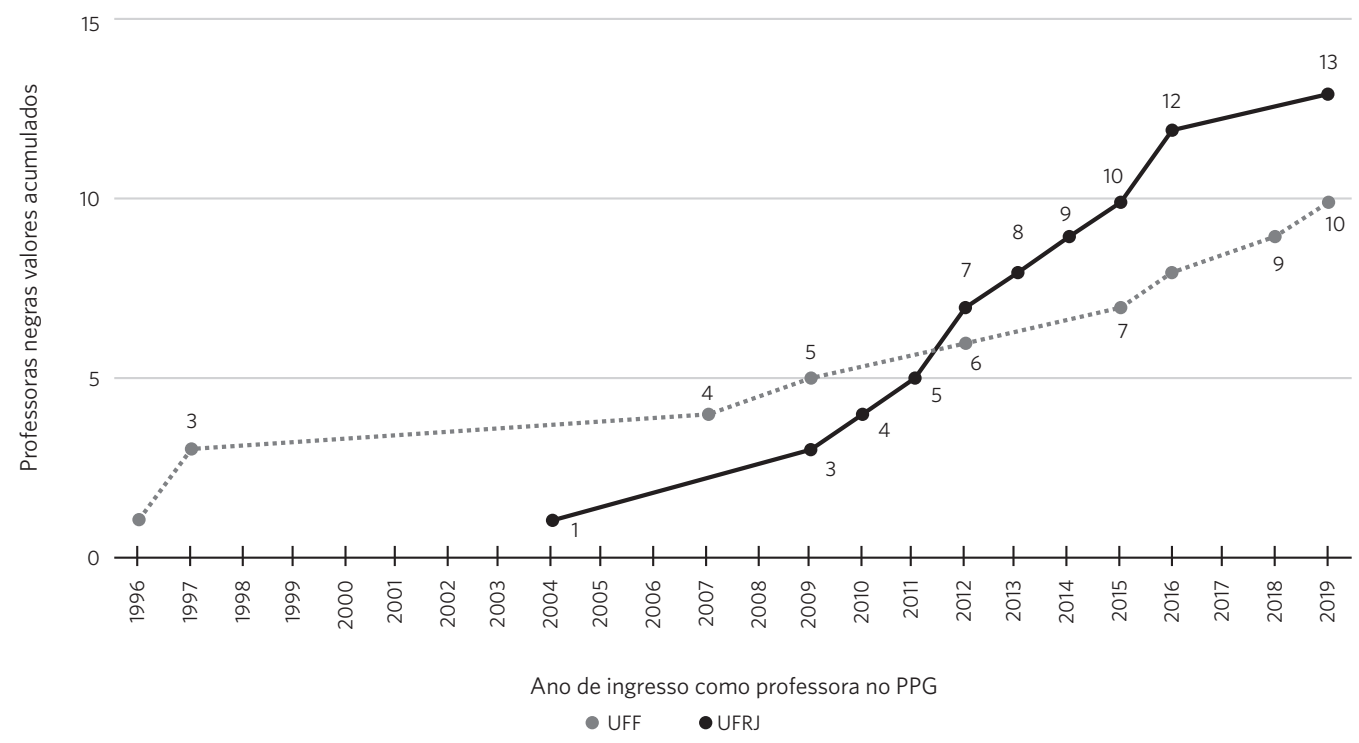


O gráfico 3 apresenta o número de professoras negras, de acordo com o ano de ingresso como professoras no PPG analisado. A leitura do gráfico permite inferir que, na UFF, as professoras negras evoluíram na carreira, no contexto de seus PPG, de forma mais acelerada, nos últimos 10 anos. Assim, pode-se afirmar que os mecanismos de discriminação indireta ${ }^{11}$ contribuem para a menor velocidade do desenvolvimento da carreira acadêmica de profissionais negras nas instituições de maior prestígio.

Uma das possíveis explicações é o ideário de que essas pessoas seriam menos aptas a desempenhar cargos de maior responsabilidade, levando-as ao sobre-esforço de provar a sua capacidade técnico-intelectual a todo tempo, corroborando o exposto por Ratts ${ }^{25}$ e Euclides, Santos Silva e Da Silva ${ }^{26}$ sobre os mecanismos institucionais internos para a reprodução do racismo.

Assim, também é possível conjeturar que existe uma relação diretamente proporcional entre prestígio/tamanho da instituição e ausência de professoras negras em PPG, o que confirma os resultados parciais de uma pesquisa em andamento, realizada pelo grupo de trabalho das autoras deste artigo, que assinala menor dificuldade no acesso de pesquisadores negros e negras a cargos docentes de magistério superior em universidades menores e interiorizadas - e, portanto, de menor prestígio - em relação às mais antigas e tradicionais localizadas nas grandes metrópoles. Essa hipótese ainda merece maior análise e reflexão e será objeto de estudo posterior, quando o tratamento dos dados de todos os PPG do estado do Rio de Janeiro for finalizado.

\section{Considerações finais}

Neste trabalho, debruçou-se sobre as dinâmicas geradas pelo racismo e sexismo no acesso a cargos altamente qualificados e intelectualizados no universo acadêmico do estado do Rio de Janeiro. Apesar da análise ter-se voltado apenas para duas universidades públicas, na área de ciências da saúde, acredita-se que, pelo peso dessas instituições, tanto em tamanho como em importância acadêmico-científica, os dados e as análises aqui apresentados podem proporcionar uma compreensão bastante ampla da problemática.

A abordagem exposta permitiu delinear alguns elementos que evidenciam os efeitos do racismo estrutural e da feminização do cuidado em relação às carreiras profissionais de cientistas e intelectuais negras nas áreas da saúde. Observou-se, assim, que as mulheres são maioria do corpo docente da área, sendo $60 \%$ na UFRJ e $63 \%$ na UFF. Nesse sentido, os cursos das áreas de enfermagem e nutrição concentram não só as mulheres como também as mulheres negras.

A perspectiva interseccional adotada a partir de autoras/es negras/os foi fundamental tanto para abordar criticamente os contextos sociais e institucionais estudados quanto para conduzir o perfilamento dos PPG, observar as desigualdades raciais e de gênero no acesso a cargos de magistério superior na pós-graduação, além de identificar o lugar do 'cuidado' da maioria das docentes negras em exercício.

A partir dessa perspectiva, pode-se observar que, se bem as mulheres são maioria nos PPG da área, a presença de pesquisadoras e intelectuais negras ainda é ínfima. Na UFRJ, dos 472 docentes, apenas 10 correspondem a esse grupo étnico-racial; na UFF, são 13 docentes, ocupando 16 das 273 vagas. Quando se opta por um recorte de gênero, as pesquisadoras negras continuam em desvantagem: são $3,58 \%$ das docentes, entre as mulheres, na UFRJ; e 9,3\% na UFF. Ou seja, mesmo analisando somente o universo feminino, as pesquisadoras negras não chegam a ocupar nem 10\% desses postos altamente qualificados na carreira acadêmica.

Quando se remeteu à especificidade da medicina (I, II e III), encontrou-se apenas 1 pesquisadora negra entre os 225 docentes da UFRJ, e 2 na UFF, entre 118 docentes credenciados nos PPG dessa instituição. Mesmo na área de enfermagem, que concentra o maior número de pesquisadoras negras, esse número ainda é baixo. Na UFRJ, quatro docentes negras são credenciadas nessa área; na UFF, são seis 
*Orcid (Open Researcher and Contributor ID). pesquisadoras nos PPG da área (ciências do cuidado em saúde e enfermagem assistencial); e três em ciências da nutrição.

O racismo desponta como importante sistema de poder, operando no contexto institucional e disciplinar. Neste último, associado ao sexismo que determina as hierarquias de gênero nas áreas de saúde. Observa-se um aumento do número de professoras negras a partir da implementação das políticas de ações afirmativas, o que permite discutir sobre seus importantes efeitos no combate às desigualdades raciais, mas ainda insuficientes.

Sobre as limitações do estudo, cabe realizar algumas considerações. A primeira é relativa às fontes consultadas para extrair os dados primários. Tanto as Plataformas Lattes e a Sucupira como os sites institucionais de cada PPG, apesar de serem oficiais e as fontes mais confiáveis disponíveis publicamente, apresentaram desatualização, desativação de links e outros problemas de manutenção dos conteúdos digitais. Também se reconhece que, nessa etapa, não foi incluída a autodeclaração étnico-racial das pesquisadoras, o que está planejado para ocorrer na próxima fase da pesquisa, assim como as entrevistas com as docentes interessadas em contribuir com o estudo.

Além disso, nunca é demais assumir a especificidade da pesquisa, uma vez que os dados são específicos dos PPG e das universidades abordadas. Nesse sentido, não se buscou generalizar os resultados, apesar de se acreditar que são contribuições úteis a trabalhos futuros preocupados com a temática. Por último, assume-se que é necessário aprofundamento na perspectiva macroinstitucional ao abordar a presença/ ausência de professoras negras para conhecer de forma mais apurada e pertinente a complexidade das relações étnico-raciais, de gênero e suas interseções no ambiente acadêmico.

Assim, trabalhos futuros poderão consolidar as informações e os resultados aqui apresentados, sendo fundamental maior aproximação, de cunho qualitativo, com as docentes negras e seus contextos imediatos de atuação. Acreditase que, dessa forma, será possível conhecer outras dimensões também transversais, como, por exemplo, as trajetórias profissionais e pessoais, as agendas de pesquisa e as estratégias de atuação individuais e coletivas.

Nesse sentido, pesquisas que futuramente abordem as formas de colaboração a partir de indicadores de pesquisa, ensino e extensão, como também de produção científica, poderão fornecer desdobramentos fundamentais para compreender não só como o racismo estrutural se reproduz na academia, mas também, principalmente, como se colocam em prática estratégias de enfrentamento, resistência e reexistência.

\section{Colaboradoras}

Sousa ALN (0000-0003-1924-5297)* contribuiu para concepção, desenho do estudo, análise e interpretação dos dados, elaboração do rascunho, revisão crítica do conteúdo e aprovação da versão final do manuscrito. Cabral LFE (00000003-1767-141X)* contribuiu para concepção, desenho do estudo, análise e interpretação dos dados, elaboração do rascunho, revisão crítica do conteúdo e aprovação da versão final do manuscrito. Moreira JM (0000-0001-9838-9613)* contribuiu para revisão crítica do manuscrito, coleta e interpretação dos dados, elaboração do rascunho, revisão crítica do conteúdo e aprovação da versão final do manuscrito. Weihmüller VC (0000-0002-1559-8354)* contribuiu para revisão crítica do manuscrito, coleta e interpretação dos dados, elaboração do rascunho, revisão crítica do conteúdo e aprovação da versão final do manuscrito. Rodrigues MMS (0000-0003-4240-7733)* contribuiu para coleta e interpretação dos dados, revisão crítica do conteúdo e aprovação da versão final do manuscrito. Araujo GG (0000-00016646-4076)* contribuiu para coleta e interpretação dos dados, revisão crítica do conteúdo e aprovação da versão final do manuscrito. Macedo BCC (0000-0001-9587-4189)* contribuiu para coleta e interpretação dos dados, revisão crítica do conteúdo e aprovação da versão final do manuscrito. 


\section{Referências}

1. Instituto Brasileiro de Geografia e Estatística. Projeção da População do Brasil e das Unidades da Federação. Brasília, DF: Brasília; 2017. [acesso em 2020 ago 2]. Disponível em: http://www.ibge.gov.br/apps/ populacao/projecao/.

2. Instituto Brasileiro de Geografia e Estatística. Censo Demográfico 2010. Brasília, DF: 2010. [acesso em 2020 ago 2]. Disponível em: http://www.ibge.gov.br/ home/estatistica/populacao/censo2010/default.shtm.

3. De Assis C. Gráfico: gênero e raça na ciência brasileira. Gênero e Número. 2018 jun 2. [acesso em 2020 jul 28]. Disponível em: http://www.generonumero. media/grafico-genero-e-raca-na-ciencia-brasileira/.

4. Santos MF. Ações afirmativas e racismo estrutural: considerações sobre o sistema de cotas na pós-graduação. In: Sousa ALN, organizador. Povos e saberes indígenas e afrodiaspóricos: educação, cultura e políticas públicas. Rio de Janeiro: Gramma; 2020.

5. Venturini AC. Ações afirmativas para pós-graduação: desenho e desafios da política pública. In: Anais $41^{\circ}$ Encontro Anual da ANPOCS. Universidade Federal de Alagoas; 2017. [acesso em 2020 jul 9]. Disponível em: https://evento.ufal.br/anaisreaabanne/.

6. Ferreira L. Menos de 3\% entre docentes da pós-graduação, doutoras negras desafiam racismo na academia. Gênero e Número. 2018 jun 20. [acesso em 2020 jul 4]. Disponível em: http://www.generonumero.media/menos-de-3-entre-docentes-doutoras-negras-desafiam-racismo-na-academia/.

7. Scheffer M, organizador. Demografia Médica no Brasil 2018. São Paulo: Departamento de Medicina Preventiva da Faculdade de Medicina da USP; Conselho Regional de Medicina do Estado de São Paulo; Conselho Federal de Medicina; 2018. 286 p. [acesso em 2020 ago 11]. Disponível em: http://www.epsjv.fiocruz.br/sites/default/files/files/DemografiaMedica2018\%20(3).pdf.
8. Machado $\mathrm{MH}$, organizador. Perfil da enfermagem no Brasil. Rio de Janeiro: NERHUS; DAPS; ENSP, Fiocruz; 2017. [acesso em 2020 jun 29]. Disponível em: http://www.cofen.gov.br/perfilenfermagem/pdfs/ relatoriofinal.pdf.

9. Almeida AH. Mulheres negras e a realidade da enfermagem no Brasil. Núcleo Assessoria, Capacitação e Especialização à Central de Material e Esterilização (NASCE-CME). [acesso em 2020 jun 15]. Disponível em: http://nascecme.com.br/mulheres-negras-e-a-realidade-da-enfermagem-no-brasil/.

10. Campos P. História social da enfermagem brasileira: afrodescendentes e formação profissional pós-1930. Rev Enf. Ref. 2012; III(6):167-77.

11. Almeida S. Racismo Estrutural. São Paulo: Jandaíra; 2020.

12. Carneiro S. Racismo, sexismo e desigualdade no Brasil. São Paulo: Selo Negro Edições; 2011. (Consciência em debate).

13. Instituto Brasileiro de Geografia e Estatística. A Pesquisa Nacional por Amostra de Domicílios Contínua. PNAD Contínua. Mercado de Trabalho Brasileiro. $1^{\circ}$ trimestre de 2019. Brasília, DF: 2019. [acesso em 2020 maio 28]. Disponível em: https://agenciadenoticias. ibge.gov.br/media/com_mediaibge/arquivos/8ff410 04968ad36306430c82eece3173.pdf.

14. Instituto Brasileiro de Geografia e Estatística. Pesquisa Nacional de Amostras por Domicílio Contínua. PNAD Contínua. Educação 2018. Brasília, DF; 2018. [acesso em 2020 maio 25]. Disponível em: https://agenciadenoticias.ibge.gov.br/media/com mediaibge/arquivos /00e02a8bb67cdedc4fb22601ed264c00.pdf.

15. Da Silva J. Doutoras professoras negras: o que nos dizem os indicadores oficiais. Perspectiva. 2011 [acesso em 2020 ago 30]; 28(1). Disponível em: http://www. periodicos.ufsc.br/index.php/perspectiva/article/ view/19459. 
16. Parent in Science. Produtividade Acadêmica durante a pandemia: efeitos de gênero, raça e parentalidade. Brasil: Parent in Science. 2020. p. 13. [acesso em 2020 ago 8]. Disponível em: https://327b604e-5cf4492b-910b-e35e2bc67511.filesusr.com/ugd/0b341b_8 lcd8390d0f94bfd8fcdl7ee6f29bc0e.pdf?index=true.

17. Davis AY. Mulheres, cultura e política. São Paulo: Boitempo; 2017.

18. Crenshaw K. Documento para o encontro de especialistas em aspectos da discriminação racial relativos ao gênero. Rev. Estud. Fem. 2002; 10(1):171-88.

19. Crenshaw K. A intersecionalidade na discriminação de raça e gênero. In: Cruzamento: raça e gênero. Brasília, DF: Unifem; 2004. p. 7-16.

20. Hill CP. Em direção a uma nova visão: raça, classe e gênero como categorias de análise e conexão. In: Montero R, organizador. Reflexões e práticas de transformação feminista. São Paulo: SOF; 2015. (Série Economia e Feminismo. V. 4. Cadernos Sempreviva).

21. hooks b. Intelectuais negras. Rev Estud. Fem. 1995; 3(1):464.

22. Gonzalez L. Racismo e sexismo na cultura brasileira. Rev. Ciênc. Soc. Hoje, Anpocs. 1984; 223-44.

23. Davis AY. Mulheres, raça e classe. São Paulo: Boitempo; 2016.

24. Gomes NL. Movimento negro e educação: ressignificando e politizando a raça. Edu. Soc. 2012; 33(120):727-44.

25. Ratts AJP. Corpos negros educados: notas acerca do movimento negro de base acadêmica. Nguzu Rev Núcleo de Est. Afro-Asiáticos da UEL. 2011; 1(1):29-39.
26. Euclides MS, Silva SPS, Da Silva J. Quando se é mulher, negra, doutora e professora universitária: uma travessia marcada por disputas. In: Anais da Reunião Equatorial de Antropologia e da Reunião de Antropologia do Norte e Nordeste. Universidade Federal de Alagoas; 2016. [acesso em 2020 jul 9]. Disponível em: https://evento.ufal.br/anaisreaabanne/.

27. Schifini LRC, Rodrigues RS. Política de avaliação de periódicos nas áreas de medicina: impactos sobre a produção editorial brasileira. Perspec. Ciênc. Inf. 2019; 24(4):78-111.

28. Brasil. Regulamenta o procedimento de heteroidentificação complementar à autodeclaração dos candidatos negros, para fins de preenchimento das vagas reservadas nos concursos públicos federais, nos termos da Lei no ${ }^{\circ}$ 2.990, de 9 de junho de 2014. Brasília, DF: Ministério do Planejamento, Orçamento e Gestão (MPOG); Secretaria de Gestão de Pessoas; 2018. [acesso em 2020 jul 21]. Disponível em: http://www. dpu.def.br/images/stories/Infoleg/2018/04/10/portaria_mpog2.pdf.

29. Marcondes MM. O cuidado na perspectiva da divisão sexual do trabalho: contribuições para os estudos sobre a feminização do mundo do trabalho. In: Yannoulas SC, organizador. Trabalhadoras - Análise da Feminização das Profissões e Ocupações. Brasília, DF: Editorial Abaré; 2013. p. 251-80.

Recebido em 01/09/2020

Aprovado em 20/05/2021

Conflito de interesses: inexistente

Suporte financeiro: não houve 